\title{
La escuela un lugar de lugares: testimonios de niñas, niños y adolescentes en zonas de conflicto en Colombia The School, Place of Places:
} Testimonies of Children and Adolescents in Conflict Zones in Colombia

\author{
Yuri Constanza Páez Triviño \\ Departamento de Investigaciones Educativas, Cinvestav, México \\ yconstanzap@gmail.com \\ ORCID 0000-0003-4251-4950
}

\section{RESUMEN}

En este artículo se reflexiona sobre la manera en que niñas, niños y adolescentes [NNA] describen la escuela y las emociones que los espacios escolares les producen. Se eligió uno de los ejes de análisis de una investigación más amplia, realizada mediante una etnografía en dos escuelas rurales en tiempos del postacuerdo en Guaviare, Colombia, desarrollada entre 2018-2020. Se recopilaron entrevistas, escenas etnográficas, narrativas orales, dibujos, fotografías y textos escritos de los estudiantes usando una sensibilidad etnográfica. En el análisis de estos registros se propone un acercamiento a los lugares de lo escolar y la vida cotidiana de estos actores. Asimismo, se presentan reflexiones centradas en mostrar los lugares de la escuela y las escuelas en sí mismas, entendidas en términos de Massey (2009), como un producto de relaciones en una complejidad de redes, intercambios y conexiones. El conflicto armado, la pobreza, el desamparo del Estado y la falta de infraestructura atraviesan la relación con el espacio que tienen los y las estudiantes con sus instituciones escolares.

Palabras clave: escuela, conflicto armado, educación rural, etnografía, Colombia

\begin{abstract}
This paper examines how children and adolescents describe the school and the emotions that school spaces produce in them. We chose one of the axes of analysis of a wider research, an ethnography of two rural schools in Guaviare, Colombia, during the post-agreement, in 2018-2020. We collected interviews, ethnographic scenes, oral narratives, drawings, photographs, and written texts of the students with an ethnographic sensitivity. In the analysis of these records, we advance an approach to the school places and the daily life of these actors. Likewise, we present reflections focused on showing the school places and the schools themselves, understood in terms of Massey (2009), as a product of relationships in the complexity of networks, exchanges, and connections. The armed conflict, poverty, the helplessness of the State, and the lack of infrastructure cut across the relationship with the space that students have with their school institutions.
\end{abstract}

Keywords: school, armed conflict, rural education, ethnography, Colombia 


\section{INTRODUCCIÓN}

En Colombia, el fenómeno de violencia ha estado asociado a la evidente precariedad o ausencia del Estado y a la acción de las guerrillas revolucionarias y de las fuerzas que la enfrentan: el ejército y las poderosas organizaciones de "autodefensa" o paramilitares (Pécaut, 2001). Estos actores han generado en todo el territorio nacional formas de violencia indistintas que pasan por masacres, desaparición forzada, desplazamiento masivo, entre otros. Herrera (2016, pp. 21-22), lo explica de esta manera:

La violencia política en la cual se enmarca el actual conflicto armado se remonta a más de cinco décadas y ha arrojado 220000 muertos tan sólo entre 1985 y 2013, así como 25000 desaparecidos y cinco millones y medio de desplazados. Al tiempo que las personas directamente afectadas por el conflicto abarcan $15 \%$ del total de la población (Semana, 2015, ed. 1753, p. 107). Asimismo, en discusiones respecto al postconflicto, se ha mencionado en el Congreso de la República que el número de municipios con mayor afectación del conflicto armado oscila entre 368 y 395, en los cuales habitan alrededor de 15 millones de colombianos -recordemos que la totalidad de la población asciende a más de 48 millones (Pertuz et al., 2019, p. 22).

Estas estadísticas llevarían a pensar que es casi imposible un acuerdo de paz que perdure y permita a la población más afectada por la guerra mejorar sus condiciones de vida. Sin embargo, desde 1982 los gobiernos nacionales han propuesto condiciones más o menos favorables para poner en marcha procesos de paz con diferentes grupos armados, guerrillas o paramilitares.

Entre los efectos más notorios de esta violencia están las huellas que ha dejado el conflicto armado en las escuelas. De acuerdo con Romero (2013, p. 62), Colombia es uno de los países de Latinoamérica que registra mayor número de atentados contra el espacio escolar, "verificable en ataques armados a las infraestructuras, minado de zonas adyacentes a los perímetros escolares, presencia de actores armados tanto regulares como no oficiales, uso del espacio escolar para el ejercicio propagandístico y de difusión de todo tipo de mensajes y de presión y/o aleccionamiento para las comunidades". 
Los actores armados -llámense guerrillas, paramilitares o incluso Ejército Nacional- han restringido el acceso y la movilidad en muchas zonas del país, y han generado fronteras invisibles que impiden, incluso, el ingreso a las instituciones escolares; de esa manera, la escuela queda controlada por el grupo armado que lidera en cada territorio. De acuerdo con la Dirección de Minas del Gobierno de Colombia, un total de 1159 niños, niñas y adolescentes fueron víctimas de minas antipersonales y restos de explosivos entre 1990 y 2016; la mayoría en zonas rurales, donde estos artefactos se instalan en caminos y veredas, áreas boscosas y alrededores de lugares estratégicos, incluyendo el camino a la escuela (González, 2016).

Otra dimensión de análisis de este fenómeno tiene que ver con la agresión, detención ilegal, secuestro, desaparición forzada o tortura a miembros del alumnado y docentes de las escuelas. El sindicato de la Federación Colombiana de Educadores (Fecode, 2016, p. 3) expone que entre el 1 de enero de 1985 y julio de 2016, "1076 docentes han sido asesinados, 1800 desplazados, 50 desaparecidos, 70 exiliados y 6000 amenazados". También, describe otras situaciones que atraviesan las escuelas:

El control de la enseńanza por parte de los actores armados; priorización del presupuesto de guerra sobre el presupuesto de la educación; escuelas entre los fuegos cruzados, rodeadas de trincheras, lugares de reunión convocadas por los militares, los paramilitares y los guerrilleros. Deserción de estudiantes por el desplazamiento de las comunidades. La escuela recibe en sus aulas a la población docente y estudiantil desplazada y víctima de la guerra y, también, a los hijos de uno y otro bando armado (Fecode, 2016, p.3).

Ante un conflicto tan prolongado y polarizado, el riesgo de maestros, directivos y alumnado es inminente y los convierte en un objetivo militar, lo que ha generado zozobra e incertidumbre sobre las formas de hacer escuela en estos territorios. ${ }^{1}$

\footnotetext{
${ }^{1}$ Otras investigaciones han dado cuenta de las condiciones de maestros y estudiantes en territorios atravesados por el conflicto armado en Colombia, entre las que cabe mencionar los trabajos de González (2016), Ospina et al. (2016), Riaño et al. (2003), Restrepo (2015), entre otros.
} 
Con lo anterior, el objetivo de este artículo es dar cuenta de las perspectivas que los NNA tienen frente a la escuela en contextos atravesados por violencia armada. La investigación tuvo lugar en el Departamento del Guaviare. De acuerdo con Palomino (2018), este lugar ha tenido por décadas una gran incidencia del conflicto armado debido a su aislamiento con el centro del país y al abandono estatal. Después de la firma del Acuerdo de Paz entre el Gobierno y las Fuerzas Armadas Revolucionarias de Colombia-Ejército del Pueblo (FARC-EP), cientos de exguerrilleros desmovilizados se concentraron en dos espacios territoriales del municipio, pero el problema del aislamiento sigue latente en sus corregimientos y veredas, y los hace susceptibles al abandono y la ilegalidad. En este contexto, se seleccionaron dos escuelas oficiales: la Institución Educativa (IE) La Planicie y La Ribera. ${ }^{2}$ Estas instituciones tenían la particularidad de contar con estudiantes que son hijos e hijas de excombatientes de las FARC; excombatientes menores de edad; hijos e hijas de población víctima de la violencia (ya sea desplazados, con padres o madres fallecidos en contextos de guerra, u otros); e hijos e hijas de campesinos de la zona.

Presento primero un contexto general sobre la firma del Acuerdo de Paz que se llevó a cabo en Colombia en 2016 y los efectos que esto trajo en las zonas de mayor impacto de la violencia en todo el territorio. Anudado a esto, planteo algunas perspectivas socioculturales sobre la escuela y, posteriormente, profundizo en el enfoque metodológico utilizado para, por último presentar los resultados de la investigación desde las narrativas producidas por los y las estudiantes de las dos escuelas rurales.

\section{PERSPECTIVAS TEÓRICAS}

Hablar de las escuelas en medio del conflicto armado es un reto importante para la investigación educativa, en especial en el marco de un acuerdo de paz firmado hace cuatro años en Colombia.

\footnotetext{
${ }^{2}$ Las dos escuelas La Planicie y La Ribera fueron renombradas en la investigación para proteger las identidades de los y las estudiantes y demás personas de la comunidad que hicieron parte de la investigación (una condición in situ de este tipo de investigaciones en territorios atravesados por hechos violentos).
} 
Para 2016, se vivía en todas las regiones del país una tensión sobre el destino de los diálogos de paz logrados entre la guerrilla de las FARC-EP y el gobierno de Colombia, encabezado entonces por el presidente Juan Manuel Santos. En noviembre de ese año se firman los acuerdos, a pesar de la derrota en un plebiscito propuesto por el gobierno nacional. Como parte del acuerdo, los exguerrilleros de las FARC retornaron a la vida civil y se reubicaron en diferentes zonas rurales llamados Espacios Territoriales de Capacitación y Reincorporación (ETCR), donde se aseguraría la educación, vida productiva y actividad política, entre otros: "Cientos de ellos y ellas llegaron allí con el camuflado, un rifle a cuestas y muchas ilusiones sobre lo que implicaría volver a una vida sin armas" (Páez, 2020, p.12).

Las diferencias del actual gobierno frente a los acuerdos de paz han dificultado el trabajo de los excombatientes en las zonas rurales; por ejemplo, algunos no han podido incorporarse a las escuelas para terminar su bachillerato; no tienen los recursos económicos suficientes para los proyectos productivos agropecuarios y, en el peor de los casos, han sufrido amenazas e intimidación por otros grupos violentos, incluida la llamada disidencia de las FARC, que son guerrilleros que no se incorporaron al proceso de paz. Guevara (2019, s. p.) señala:

De acuerdo con Antonio Guterres, la seguridad de los líderes sociales y defensores de los derechos humanos, así como de los excombatientes, está intrínsecamente vinculada a la seguridad de sus comunidades. "A pesar de las mejoras generales en la seguridad registradas tras el Acuerdo de Paz, las comunidades continúan siendo atacadas por grupos armados ilegales y organizaciones criminales en áreas donde la limitada presencia del Estado ha dejado vacíos institucionales y donde la falta de oportunidades económicas ha hecho que las comunidades sean vulnerables a las economías ilícitas", aseguró el Secretario General.

En este escenario, las instituciones educativas están enfrentando los cambios que ha traído la firma del acuerdo de paz, en particular, en su rol en la transformación de la vida de los NNA del país, sobre todo de aquellos que enfrentan las particularidades de las huellas 
que el conflicto ha dejado en las personas; "muchos de los niños y las niñas afectados por la violencia no cuentan con procesos de alfabetización, y solamente han conocido la guerra como manera de subsistencia” (Ospina, López, Burgos y Madera, 2016, p. 945).

La apuesta real de las instituciones es que comprender el conflicto armado permitirá encontrar nuevas maneras de enunciación para quienes han hecho parte de la guerra. Este escenario desconocido y bastante amplio dará la oportunidad de generar propuestas coherentes con las necesidades de las comunidades en sus territorios a diferentes sectores educativos (Páez, 2020).

Una estrategia que determinó el Gobierno Nacional fue la Cátedra de la Paz, un espacio curricular que se instaló en todas las instituciones públicas y privadas del país. Actualmente, esta cátedra permite espacios de reflexión, diálogo y pensamiento crítico sobre la historia y las memorias de la guerra en el país en algunas instituciones escolares. Se busca incentivar, desde las aulas, una cultura de paz basada en la exigencia de los derechos humanos, los deberes familiares y ciudadanos y la disposición de una resolución pacífica en las prácticas cotidianas de la escuela (Pertuz et al., 2019).

Con la idea de alimentar estas discusiones sobre las formas en las que se ha estado haciendo escuela en las regiones del país y de visibilizar, desde la experiencia en territorio, las condiciones políticas y educativas que se plantearon en el postacuerdo, esta investigación planteó como principal cuestionamiento: ¡cómo hacer escuela en espacios atravesados por conflictos que potencialmente amenazan el trabajo de la institución escolar?

Para la aproximación a la experiencia escolar se parte del trabajo de los filósofos belgas Masschelein y Simons (2018, p. 23), quienes definen la escuela como "una disposición particular de tiempo, espacio y material donde los jóvenes son expuestos a la compañía (de algo) del mundo, de un modo específico”. Entonces, ¿cuál es ese "algo del mundo" con el que los y las jóvenes se conectan en las escuelas colombianas?

Junto a esta pregunta emergen las ideas de Dussel (2018, p. 84), que permiten pensar la escuela como "precaria, inestable, siempre por hacerse, y también siempre a punto de ser destruida”; pues una escuela que se mantiene en medio de las transformaciones del 
conflicto armado sólo puede entenderse desde la precariedad, ${ }^{3}$ pero también desde la posibilidad de ensamblarse y ser reconstruida.

\section{ENFOQUE METODOLÓGICO}

\section{La sensibilidad etnográfica y la recuperación de narrativas}

En este estudio se da cuenta de un eje de análisis de la investigación titulada: "Esto es tener ganas de estudiar. Una etnografía de dos escuelas rurales en tiempos del postacuerdo en Colombia”. El enfoque metodológico implicó pensar las formas de investigar en territorios en medio del conflicto. El Departamento del Guaviare, en Colombia, a pesar del trabajo de las comunidades por incorporarse a un proceso de paz activo y contar con dos ETCR como espacios de reincorporación de excombatientes de las FARC, se ve enfrentado a la lucha entre grupos armados que buscan en este territorio las facilidades del cultivo y tráfico de cocaína hacia Venezuela y otros países limítrofes.

En ese sentido, una perspectiva etnográfica permitió acercarse a los actores, a las concepciones, a los significados, a los sentidos y a las situaciones que se revelan en campo; de manera que lo que haría el etnógrafo es documentar lo no-documentado de la realidad social y eso no-documentado puede ser lo familiar, lo cotidiano, lo oculto, lo inconsciente (Rockwell, 2009).

Además de esta mirada etnográfica, implicó pensar las condiciones de trabajo con los y las estudiantes desde las restricciones que plantearon las directivas de las dos instituciones para acceder a los alumnos de la escuela. "Las reglas fueron claras: no entrevistarlos, no tomarles fotografías ni videos donde ellos pudieran ser identificados y, además, diseñar una estrategia de intervención con ellos en aula" (Páez, 2020, p. 138). Estas restricciones se fundamentaron en que la mayoría de los y las niñas eran menores de edad; algunos se encontraban en procesos de reincorporación a la vida civil (es decir, que

\footnotetext{
${ }^{3}$ Ampliando la idea de Dussel (2018, p. 88), "sostener ese ensamblaje demanda muchos esfuerzos: el esfuerzo de los profesores para circunscribir a los niños y niñas a ciertas formas de trabajo, el balizamiento o vigilancia de una cierta frontera de lo que se puede hacer o no hacer en la escuela, la organización de rutinas, rituales, modos de hablar, de vestir, la disposición de los cuerpos en el espacio, la reforma de la arquitectura escolar para hacer lugar a estas necesidades".
} 
hacían parte de los excombatientes menores de edad que ya estaban en el sistema escolar) o en que, por las condiciones de las escuelas, no había la opción de solicitar el consentimiento de los padres, madres o tutores (tanto La Planicie como La Ribera son escuelas con internados). Estas medidas, más que restrictivas, eran preventivas, pues un investigador, como agente externo, podía ser juzgado como reclutador de menores en la zona, lo que podría llevar a confundirlo como infiltrado de organizaciones al margen de la ley.

Según el Centro Nacional de Memoria Histórica (CNMH, 2017, p. 248) de Colombia, tanto el reclutamiento como la utilización de jóvenes "no han sido operaciones aleatorias, pues han respondido a un conjunto de definiciones y acciones relacionadas con las apuestas estratégicas, políticas y militares de los grupos armados y que se desarrollan en el marco de la cotidianidad de los niños, niñas y adolescentes". No es un secreto que las escuelas han sido el foco de mayor atención para esta práctica.

Frente a estas condiciones, el reto fue diseñar registros que permitieran producir y recuperar la palabra de NNA en las escuelas. En este caso particular, se optó por diseñar y desarrollar seis talleres -uno por grado- que permitieran un acercamiento a la palabra (al testimonio) para que, de esta manera, se complementara con los registros etnográficos logrados hasta ese momento, dentro y fuera de la escuela.

Cada taller estuvo dividido en dos sesiones y "el objetivo era indagar cómo NNA describen su escuela y las emociones que los espacios escolares producen en ellos" (Páez, 2020, p. 139). Los fragmentos narrativos estuvieron enmarcados en tres tipos de registro: el oral, en las conversaciones informales y los espacios de aula; el escrito, a través de cartas y fotografías ${ }^{4}$ o ilustraciones. Los grados que fueron asignados para el trabajo de campo en cada escuela se distribuyeron así: en La Planicie, el aula multigrado de bachillerato, donde estaban los estudiantes de sexto a noveno y los grados cuarto y quinto de primaria (que también estaban en una sola aula). En La Ribera se hizo trabajo en las aulas multigrado de décimo y onceavo (media superior), octavo y noveno y cuarto y quinto grado de primaria. Para cada grado se organizó una consigna diferente.

\footnotetext{
${ }^{4}$ Una foto proporciona una pequeña visión que, cuando se entiende junto con otras imágenes y fragmentos narrativos, puede contarnos cómo se pronuncian los niños y su lugar en el mundo (Templeton, 2020).
} 


\section{Los contextos escolares}

Dentro del proceso de investigación, recabar información sobre las instituciones educativas donde se realizó el trabajo de campo fue otro desafío, en gran medida, porque los actores violentos han desaparecido gran parte de los documentos oficiales que contaban una parte de la historia de estas escuelas. A esto se suma que las comunidades estuvieron renuentes a contar su historia por falta de garantías y seguridad para sus familias en el territorio. Aquí presento algunas características generales de las dos escuelas y sus modalidades educativas.

Cabe mencionar que el territorio donde se encuentran las escuelas no tiene buenas condiciones de seguridad; tras dos ańos de la firma del acuerdo de paz (en 2018 cuando se hace el trabajo de campo de la investigación) varios excombatientes han sido asesinados y perseguidos, incluso al interior de los ETCR; los proyectos productivos con los que se esperaba que los campesinos de la zona se sustentaran ante la erradicación manual de coca no han funcionado, en parte por falta de apoyo de las entidades gubernamentales, y esto repercute en la economía de las comunidades. Sumado a esto, aunque los maestros, maestras y directivos intentan mantener las instituciones educativas fuera del conflicto armado, las amenazas a las instalaciones, el reclutamiento de NNA y la falta de recursos económicos no permiten un buen funcionamiento del sistema escolar en estos lugares.

\section{La escuela La Planicie}

La escuela La Planicie está ubicada en el corregimiento que lleva su mismo nombre, el cual es parte del Municipio de San José del Guaviare, Departamento del Guaviare. Es una escuela multigrado, rural, que cuenta con primaria y secundaria completas hasta grado noveno, ${ }^{5}$ a la que asisten 110 NNA, y donde se desempeńan cuatro maestras y un maestro. El edificio tiene cuatro salones, dos de ellos usados como dormitorios para el internado, un baño, un lavadero, un espacio de comedor y un aula improvisada. Cuenta, además, con

\footnotetext{
${ }^{5}$ En Colombia, la educación básica primaria comprende cinco grados - de primero a quinto-, la educación básica secundaria cuatro grados -sexto a noveno- y la educación media superior dos grados -décimo y onceavo-. Esta organización escolar aplica a todo el sistema educativo y es obligatorio para el ingreso a la educación superior.
} 
un internado que tiene 18 niñas y 17 niños, y una persona asignada como coordinadora por la Secretaría de Educación del Guaviare.

Su ubicación geográfica es importante para los habitantes de las 28 veredas aledañas desde donde llegan NNA a cursar su secundaria, pues la mayoría de estas veredas cuentan únicamente con escuelas primarias unitarias. A pesar de esta condición, la escuela no tiene una buena infraestructura física para albergar a los estudiantes.

\section{La escuela La Ribera}

La Ribera es una escuela rural, multigrado, mixta, que cuenta con preescolar, primaria, secundaria y media superior completa. Tiene 200 estudiantes, cinco maestras y cuatro maestros. Esta escuela también tiene internado y, a pesar de ser más grande que el internado de La Planicie, sólo alberga 11 estudiantes y una coordinadora.

La escuela tiene siete aulas distribuidas entre los doce grados que se ofertan. Los únicos grados que cuentan con un aula exclusiva son preescolar (Grado cero) y primero de primaria. Los demás cursos están organizados en dos grados por salón.

\section{ANÁLISIS DE NARRATIVAS COMO TESTIMONIO}

\section{"Las ecuelas como lugares de afectos"}

Gran parte del trabajo de campo que se llevó a cabo en las escuelas permitió una dinámica activa con los y las estudiantes. Ellos y ellas describieron, dibujaron y fotografiaron algunos espacios de la escuela donde fue posible desentrañar el ruido, las voces, el eco de las bancas, los abrazos, las lágrimas, los juegos, la música, el teatro, la literatura, las matemáticas y la vida misma en esos lugares que configuran su cotidianidad. Se pudieron identificar diferentes capas de significación que entrelazan lo sensorial, lo social, lo imaginativo y lo pragmático. Coincido con la idea de Rockwell (2018) en la que la escuela es un lugar en el que "nada está quieto. Todo parece ser caótico. ¿Qué orden puede haber en los arrebatos de decenas de niños que se cruzan y se tropiezan en el patio de cualquier escuela? ¿Qué habrá de interesante en sus continuas conversaciones llenas de alusiones cotidianas, mediáticas y familiares? ¿Qué está en juego en 
sus juegos inventados o reinventados?" (Rockwell, 2018, p. 240).

\section{La experiencia del internado: El relato de Laura ${ }^{6}$}

En el marco del taller de bachillerato, la consigna que se dio a los y las estudiantes fue que tomaran una o dos fotografías de su lugar preferido en la escuela y luego, con sus compañeros, contaran a todo el grupo por qué eligieron dicho espacio.

Uno de los grupos a la cabeza de Laura, una joven de 16 años de grado noveno, comentó a sus compañeros durante el taller:

- Fotografía 1. Camino hacia el río, escuela La Planicie

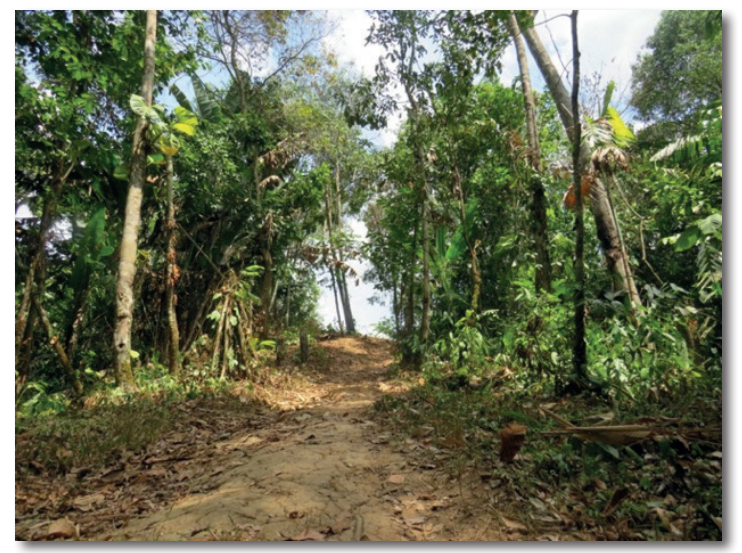

Fuente: producción de estudiantes, archivo de trabajo de campo, febrero de 2019.

SOFÍA: Bueno, elegimos esta foto (fotografía 1) entre todas las que tenemos... porque... [risas].

LAURA: La verdad, es que esa selva, ese camino significa mucho... En especial cuando vivimos aquí hace tanto tiempo. [Su tono cambió respecto a la primera oración, se notaba nerviosa].

INV [Investigadora]: ¿Pero, por qué significa mucho?

LAURA: Es que cuando uno vive toda la vida lejos de la familia y la ve cada 15 días, pues le da a uno como ... [los demás compañeros se quedaron en silencio]. 
SOFÍA: Profe, eso es como tristeza. [Uno de los compañeros le hace mofa].

LAURA: ¡Ay, Manuel es verdad!, cuando uno ve ese camino tan silencioso le dan ganas de estar en la finca, caminando junto a su mamá o sus hermanos, tranquilo, no sé, como ... [la estudiante no encuentra la palabra para expresar su emoción].

(Fragmento del diario de campo, 19 de febrero de 2019).

Desde quinto de primaria Laura estudia en el internado de La Planicie; sus padres son jornaleros y, en algunas ocasiones, son sus hermanos mayores quienes llegan a recogerla los viernes. Durante el primer taller, solicitó que le permitiera sacar una fotografía de un caño ${ }^{7}$ que está muy cerca de la escuela.

La fotografía de Laura (fotografía 1) y su equipo construye una experiencia sobre la manera de relacionarse con el mundo y plasma un instante, una memoria que a veces es peligrosamente efímera. La relación de los jóvenes con este espacio expuso, entre líneas, una emoción nostálgica sobre lo que implica estar lejos de casa; la expresión de Laura "le dan ganas de estar en la finca" orienta la lectura hacia una existencia atravesada por las largas temporadas sin su familia.

¿Qué hacer con estas emociones que transmiten los NNA en sus relatos? ¿De qué manera la escuela reconoce en la nostalgia, el miedo, el amor y el odio una parte fundamental de la vida de sus estudiantes? Es muy probable que los maestros y maestras conozcan la nostalgia de Laura y de los demás estudiantes del internado, y por esto, en medio de las limitaciones de la escuela, proponen espacios extracurriculares, apoyan las actividades cotidianas del internado y otros, con el fin de acompañar la sensación de soledad que produce estar lejos de casa (Páez, 2020).

\section{La posibilidad de volver a la escuela: el relato de Manolo}

Durante el desarrollo del mismo taller, otro grupo de estudiantes expuso junto a su fotografía las razones que los impulsan a volver a

\footnotetext{
${ }^{7}$ En la región, los caños son fuentes pequeñas de agua limpia.
} 
la escuela. Condensaron en una instalación fotográfica las dificultades que muchos jóvenes enfrentan en este territorio: lo económico, el ingreso temprano al mundo laboral, la violencia intrafamiliar y la falta de oportunidades de ingreso al sistema escolar por falta de escuelas cercanas a sus hogares.

— Fotografía 2. Parte de atrás de la escuela, huertas y tendederos. Escuela La Planicie

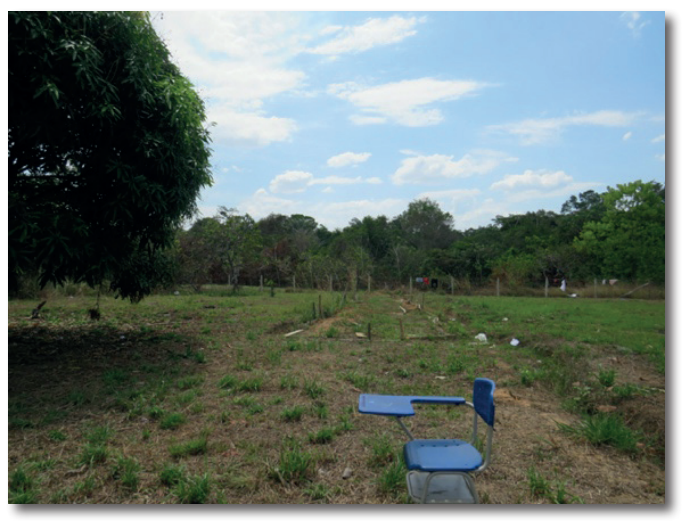

Fuente: producción de estudiantes, archivo de trabajo de campo, febrero de 2019.

El grupo de Manolo, un joven de 17 años que se encontraba en grado noveno (último año de secundaria), instaló en medio del paisaje de su espacio escolar un banco azul (fotografía 2), creando con ello una metáfora hermosa, tal vez sin querer, de la escuela rural que, en medio de todas las circunstancias, se mantiene. Didi-Huberman (2004, p. 199) menciona que cada imagen "permite hablar menos y decir mejor" o más bien, "hablar mejor de ello sin tener que decirlo". Siguiendo esta línea, para Manolo, al parecer, han existido muchas razones que lo hacen volver a este espacio, luego de tres intentos de deserción. El diálogo con los estudiantes fue el siguiente:

MANOLO: A ver, presten atención, nuestra foto se llama ... [se dirige al grupo].

JIMMY: La huerta abandonada... [risas].

MANOLO: Obvio, no... le pusimos "esto es tener ganas de estudiar" [risas] ... No, de verdad, así le pusimos y es que el puesto [banco] quiere decir estudio y, en medio del campo, es querer estudiar... 
ALBERT: Lo que pasa es que a veces Mano [Manolo] se aguanta las ganas de estudiar [risas].

MANOLO: ¡Pero siempre vuelvo!, entonces profe, ¡cómo le parece?

INV: $\quad$ Está muy bien, sale la huerta, atrás se alcanza a ver donde tienden la ropa, el cielo azul, el arbolito y en medio de todo, el puesto [el banco]... y, sí, tiene sentido lo que dicen, pero por ejemplo, ¿̇ú por qué vuelves a la escuela?

MANOLO: Yo volví aquí porque en la escuela están los amigos... Mi mamá me dijo: "mejor vaya mijo y aprende algo, algún día puede volver a trabajar” ... Pues yo en la finca me gano mi plata jornaliando, paseo ganado, corto hierba y lo que salga, así uno se gana su plata, lo que pasa es que uno se gasta eso en la tienda, jartando [bebiendo cerveza] y jugando tejo ${ }^{8}$ [risas] ... Sí, de verdad, y entonces mi má toda brava un día fue y me sacó de la tienda y me dijo: "mañana lo quiero ver que se va para la escuela”, ella me dice que voy a tener toda la vida para trabajar y un día me voy a cansar, en cambio, para estudiar, sólo voy a poder hacerlo en la escuela y cuando soy joven y bello.

INV: ¡Qué bueno que tu mamá te recordó eso!, y ustedes [dirigiéndome a los otros dos compañeros en particular y luego a los otros estudiantes en el salón], ¿quién se ha tenido que ir de la escuela y ha vuelto?, ¿por qué volvieron?, ¿qué hay aquí para que quieran volver?...

DANIEL: Profe, pues yo el año pasado estaba en séptimo y me pareció muy difícil, entonces le dije a mi má que me sacara, ella dijo: "pues se sale y se pone a trabajar". La profe Carolina me dijo que me quedara y yo todo rogado igual me fui; eso sí, el director me dijo que ahí quedaba mi cupo. Trabajé como dos semanas con

\footnotetext{
${ }^{8}$ El Tejo o Turmequé es un deporte tradicional colombiano. Hay varias adaptaciones del tejo: la más tradicional consiste en introducir el tejo dentro de un círculo metálico conocido como tejín o bosín, en los bordes del círculo se colocan cuatro mechas. Quien logre hacer explotar el mayor número de mechas, gana la partida (Secretaría Cultural, de recreación y deporte de Bogotá).
} 
mi papá en un proyecto de erradicación de coca en la finca del jefe y me pagaron una plata, me compré unos guayos, pero ya no tenía tiempo para jugar, no tenía casi amigos, sólo los de mi pá, y asimismo, le dije a mi má que quería volver. No me dejó hasta que le pedí disculpas a la profe Carolina por no hacerle caso, me metió al internado para que dejara la paseadera todos los días hasta la finca, y a mí me gusta estar en la escuela, volver es chévere, aunque perdí séptimo [risas], son chéveres los amigos, los profes, jugar futbol y las clases de aeróbicos de la profe $\mathrm{Ca}$ rolina porque me divierto. Yo ya quiero terminar noveno y seguir con el SENA [Institución de formación técnica], pero quien sabe profe...

(Fragmento del diario de campo, 19 de febrero de 2019).

La Planicie es una escuela que no se diferencia mucho de las instituciones educativas rurales, su infraestructura es básica: no hay luz, ni agua de forma permanente, las puertas se están cayendo, no hay aire acondicionado o al menos un ventilador para sobrellevar las altas temperaturas de la región, hay pocos libros, a veces faltan maestros y maestras por la lentitud y falta de garantías en los procesos de contratación de las entidades gubernamentales; a esto se suma la constante amenaza de grupos armados que se apropian de las escuelas, las atacan y destruyen, o se llevan o convencen a los jóvenes para que deserten del sistema escolar y se unan a sus filas. Lo interesante de este diálogo con los y las estudiantes es que, a pesar de todo esto, en un aula diseñada para un máximo de 25 estudiantes [aula multigrado de bachillerato], hay 38 jóvenes de sexto a noveno tratando de dar las razones suficientes para estar en la escuela, para permanecer en ese espacio que no han podido robarles por completo; un espacio que, como afirma Dussel (2020), es difícil, pero importante.

\section{La biblioteca y el parque: relatos de niños y niñas de primaria}

En el taller para primaria que se realizó en La Ribera participaron 25 estudiantes de cuarto y quinto grados de primaria, 12 nińas y 13 nińos y con edades entre los ocho y diez años. La consigna, en este 
caso, consistió en dibujar su lugar favorito de la escuela y luego compartirlo con el grupo. Se eligió hacer el momento de la socialización fuera del aula, en un espacio donde pudiéramos estar sentados en el piso, más cómodos, en especial porque las altas temperaturas en las aulas de clase podrían no favorecer el desarrollo del taller.

- llustración 1, Producción estudiante de 4․ IE La Ribera

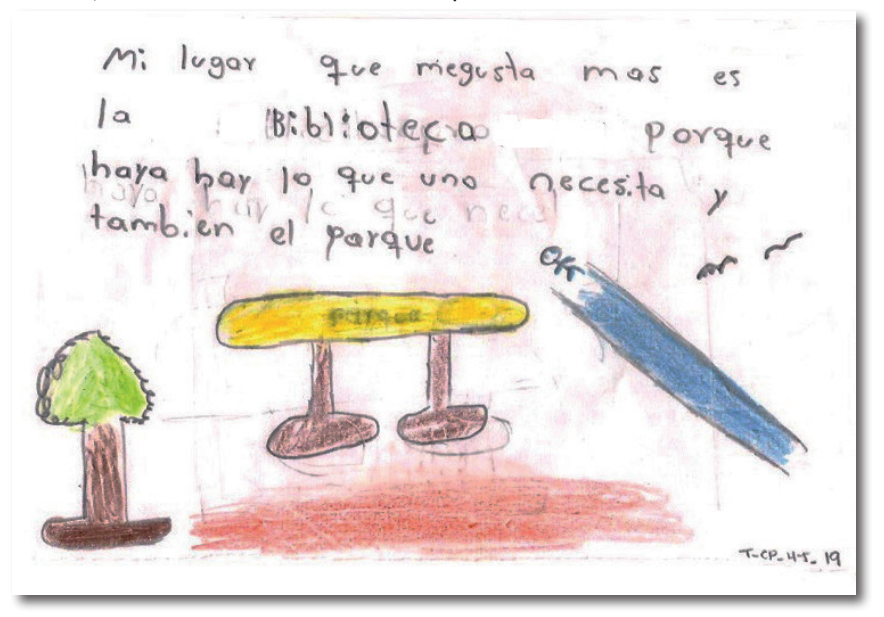

Fuente: archivo de trabajo de campo, febrero de 2019.

Fernando acompañó su dibujo (ilustración 1) de una descripción escrita y compartió lo siguiente:

FERNANDO: Miren, éste es el parque, aquí está el rodadero, los columpios y el arbolito. Aquí jugábamos antes, ahora jugamos menos y a veces corremos. El mejor de los lugares es... era, la biblioteca. ¿Se acuerdan de que veíamos películas con el profe y a veces nos mostraba libros y esas cosas?...

EST1: [Estudiante] En tercero la profesora Bertha hacía títeres allá.

EST2: $\quad$ Nos prestaban los marcadores de colores cuando la profe Victoria nos llevaba.

INV: ¿ ¿Y por qué no van a la biblioteca ahora?

EST3: $\quad$ Porque, después de lo de la bomba, la cerraron.

FERNANDO: ¡Es mentira!, es que la cerraron porque la van a remodelar. 
EST4: ¡No!, la verdad era un lugar rechévere [padre], pero ahora lo llenaron de cemento y cosas para la construcción del internado...

INV: $\quad$ Bueno, y antes de que sigamos discutiendo por qué cerraron la biblioteca, me pueden contar quiénes la pusieron como su lugar preferido [12 de 25 estudiantes levantaron la mano].

CAMILA: ¡Mire, profe, en la biblioteca yo me dibujé! (ilustración 2)

(Fragmento del diario de campo del 27 de feb/2019)

- Ilustración 2. Producción estudiante de $4^{\circ}$. IE La Ribera.

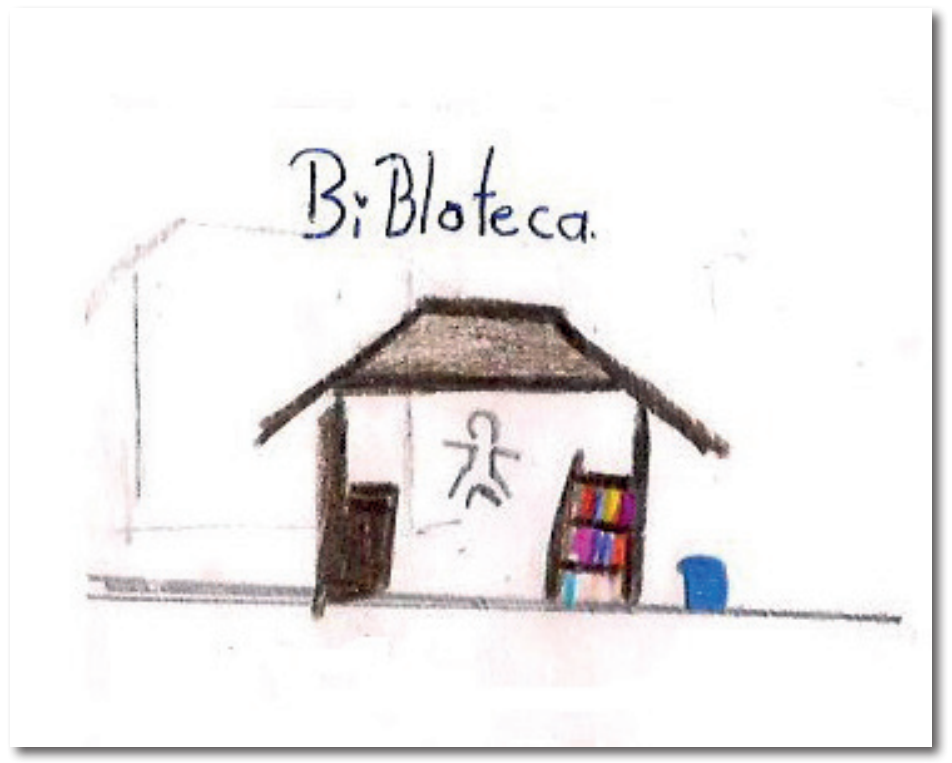

Fuente: archivo de trabajo de campo, febrero de 2019.

En el registro en campo había consignado que el director de la escuela comentó que el parque estaba a medio usar, porque se decidió poner allí el material para terminar el enrejado de la escuela, con el fin de proteger el espacio de la violencia del territorio y como esa tarea estuvo aplazada por tanto tiempo, sólo un lado del parque estaba disponible para los y las nińas. Por otra parte, de la biblioteca informó: 
MARIO: La biblioteca era un espacio muy visitado por los profesores, les gustaba llevar a los niños y habían logrado adecuarlo muy bien. Pero tenía goteras y, bueno, la verdad estaba muy cerca del lugar donde pusieron la bomba, ${ }^{9}$ los padres de familia estaban nerviosos, entonces preferí aprovechar para desocuparla y dejamos ahí, por ahora, los materiales de construcción del internado. Cuando terminen, espero darle una manita a la biblioteca y volver a ponerla (Fragmento del diario de campo del 25 de febrero de 2019).

¿Qué estaban diciendo los niños y niñas, al considerar que su lugar favorito era la biblioteca, cuando ya había pasado casi un año y aún seguía cerrada? ¿Seguían esperando la remodelación? ¿Por qué lo vincularon al atentado? Por la conversación previa con el director, se sabía que los y las estudiantes no estaban tan alejados de la realidad. Sin embargo, durante el taller, no fue posible decirles que su espacio preferido se demoraría mucho en volver a ser lo que era, que los libros no volverían allí, ni los cuentos leídos, ni los títeres, ni las películas, porque la violencia armada les había arrebatado ese espacio.

\section{EI ETCR, un lugar muy cerca de la escuela: relato de Santiago}

Durante el taller con cuarto y quinto de primaria en La Planicie, la consigna para el trabajo con los y las estudiantes fue elaborar una carta para un amigo, en la que le contarán sobre lugares, eventos o personas importantes en su escuela. Sin embargo, en el desarrollo de la actividad fue posible compartir con ellos y ellas que la investigadora venía de la Ciudad de México y, aunque era colombiana, vivía en ese país. Esa información fue trascendental para ellos, pues movilizó la oportunidad de conocer otros mundos y abrir su imaginación frente a posibilidad de compartir con un alguien que había estado no sólo fuera de su municipio o ciudad, sino del país. Por ello la carta que produjeron los niños y niñas fue dirigida a un "amigo mexicano".

\footnotetext{
${ }^{9}$ La escuela La Ribera, en 2018, había sufrido un atentado con una mina que se detonó frente al plantel durante la jornada escolar, y dejó como resultado una persona de las fuerzas militares muerta. A causa de esto, la escuela estuvo varios días cerrada.
} 
El tiempo dedicado a la escritura de la carta no permitió que los y las estudiantes pudieran compartir sus impresiones sobre el contenido de dicho material. Esto no fue impedimento para que algunos estudiantes se acercaran a la investigadora para comentar lo que allí habían escrito o dibujado.

- Ilustración 3. Producción estudiante de $4^{\circ}$. IE La Planicie.

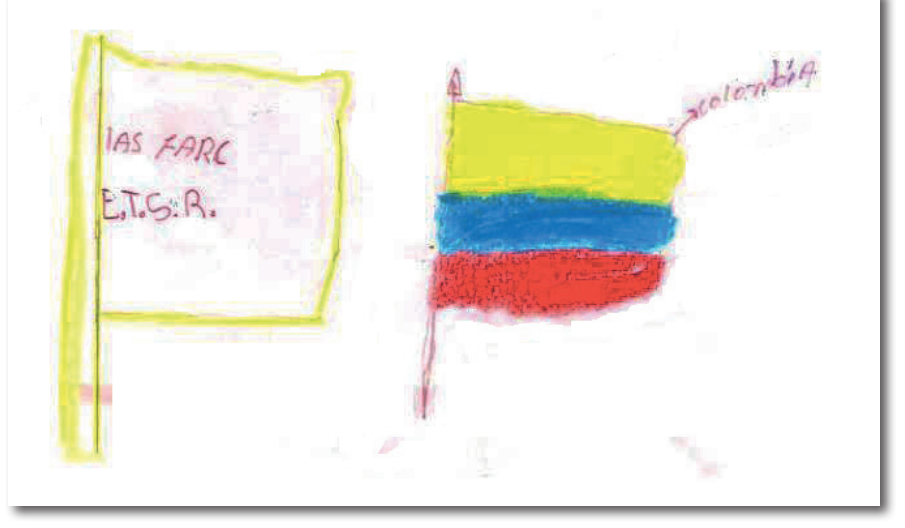

Fuente: archivo de trabajo de campo, febrero de 2019.

Este dibujo (ilustración 3) estuvo acompañado de un texto que decía lo siguiente:

Hola mi nombre es Santiago de la escuela de La Planicie. Me gusta recochar ${ }^{10}$ con mis amigos, me gusta respetar las reglas de mi colegio. Mis compañeros son Mayerli, Jhon, Carol, María, Laura, Yuliana y el profesor es Pedro (Producción estudiante de $4^{\circ}$, IE La Planicie, febrero de 2019).

La producción corresponde al trabajo hecho por Santiago, un estudiante de cuarto ańo de primaria, tiene 15 años y durante los últimos tres ańos fue guerrillero de las FARC-EP; se encontraba en La Planicie estudiando como parte de su reincorporación a la vida civil. Él comentó sobre su carta con la investigadora durante el recreo en la escuela.

\footnotetext{
${ }^{10}$ Coloquialismo colombiano que indica pasar un rato de diversión y risas con un grupo de amigos o familiares.
} 
SANTIAGO: Profe, esas cartas, ¿¿de verdad alguien más, aparte de usted, las va a leer?

INV: $\quad$ Pues qué te digo... creo que muchas personas de Colombia y de México van a leerla, no sé hasta dónde llegue... pero si me preguntaran qué significan esas banderas que dibujó allá un niño en La Planicie, ¿qué les voy a decir?

SANTIAGO: [Se quedó callado por varios segundos, se reía y volvía a quedarse callado]. Pues profe... es la bandera de la FARC, el partido político, la que está en la ETCR... ¿Sí la ha visto profe, en la cancha? [Asentí con la cabeza]. Pues es esa que significa que puede haber paz y la de Colombia porque es por un país mejor... ¿Me entiende?... Si todos estudiamos, trabajamos y aprendemos, pues, no vuelve la guerra. Por eso estamos en la ETCR. Y que los de México digan: juy, tan chévere [chido], allá vive gente que le tiene miedo a la guerra y está haciendo algo por la paz!... Chévere profe, ¿cierto?

INV: $\quad$ Si les digo todo eso, seguro querrán conocer La Planicie [él sonrió], aunque la verdad, Santiago, muchas personas en todo el mundo saben que hay personas que están haciendo proyectos muy lindos por la paz.

SANTIAGO: Sí, ojalá todos le tuvieran miedo a la guerra y por eso quisieran mejor la paz.

INV: $\quad$ Creo que... síl le tienen miedo, pero a veces no hacen muchas cosas por la paz, como muchos de los que están aquí [él de nuevo sonrió, un compañero lo llamó y se fue].

(Fragmento del diario de campo, 20 de febrero de 2019).

Para Santiago fue importante contar, en su carta, de sus compañeros, de su maestro, de las reglas que debe cumplir, que puede estar asociado al régimen militar al que perteneció. Y en la ilustración aparecen dos banderas que traducen el miedo a la guerra y la esperanza en una propuesta de paz en la que se encuentra vinculado con varios excombatientes. 


\section{REFLEXIONES FINALES}

Los cuatro relatos presentados son parte de las vivencias de los NNA que se encuentran en escuelas que han estado atravesadas por el fenómeno de la violencia armada en Colombia. Laura en particular, evidencia a través de la nostalgia la situación de muchos NNA que deben salir de sus hogares y adaptarse a los internados rurales; para muchos de ellos y ellas es la única oportunidad de acceder al sistema escolar, porque no hay suficiente oferta educativa en las regiones más alejadas de los cascos urbanos. Lo que aquí se pone también de relieve es que, a pesar de los esfuerzos de las comunidades, incluso en estos lugares, los NNA pueden estar en constante riesgo de atentados a las instalaciones escolares y reclutamiento.

Manolo evocó en el espacio escolar la experiencia cotidiana de ese lugar, su testimonio se entretejió con los trozos de otras memorias sobre lo que han vivido en la escuela -un acto performativo (Felman, 2019)-. Volver a la escuela es la oportunidad de encontrar allí un espacio que, como afirma Dussel (2020), es difícil pero importante.

El relato de Fernando muestra cómo el atentado de la bomba en La Ribera impacta sobre la forma en que los estudiantes se mueven en la escuela, el no sentirse seguros bajo el amparo de un lugar y a la vez la insistencia de ellos y ellas por volver a la biblioteca -espacio afectado por este hecho-. Los espacios son parte de ese mundo en curso, abierto al futuro y, en consecuencia, abierto también a una transformación contante (Massey, 2009).

Finalmente, a este testimonio se suma la idea de esperanza de Santiago, quien ve a la escuela como la oportunidad temporal (o por poco tiempo) de dejar atrás un pasado marcado por la guerra y un entorno familiar complejo, para convertirse en un estudiante "como todos los demás" (Masschelein y Simons, 2014).

Ezpeleta y Rockwell (1983, p. 77) reconocen que la escuela, más que un espacio físico, es un proceso de construcción social: "Más allá de Ios datos que captan las encuestas sobre materiales, anexos y condiciones de cada escuela, los edificios mismos sintetizan la historia de la instauración, negociación y apropiación cotidiana del espacio escolar". En esa medida, no es simplemente hablar de un 
banco en medio de una huerta, de una banderas izadas o de un caño cercano a la escuela; las narrativas de los y las estudiantes remiten a historias de resistencia, de luchas familiares, de una escuela que, en palabras de Herrera y Pertuz (2016), está dispuesta a seguir en medio de relatos que enmarcan posibilidades de paz y de guerra de manera simultánea.

En síntesis, hay en estas escuelas una necedad de juntarse para buscar en los intersticios un espacio de amor y, sobre todo, de esperanza, esa insistencia de maestros, maestras, niños, niñas, jóvenes, madres, padres, tutores y, en este caso, excombatientes en La Planicie y en La Ribera. En palabras de Arendt (1996), el problema de educar está en la esperanza que trae cada generación; "pero precisamente porque podemos basar nuestra esperanza tan sólo en esto, lo destruiríamos todo si tratáramos de controlar de ese modo a los nuevos, a quienes nosotros, los viejos, les hemos dicho cómo deben ser" (Arendt, 1996, p. 245). Manolo, el estudiante de grado noveno de La Planicie, prefirió llamar su fotografía "Esto es tener ganas de estudiar" como su testimonio sobre lo escolar y así, de manera espontánea, pero como una reflexión profunda, enunció -en el sentido de acto de habla- que la escuela permanece, vuelve, se suspende, pero nunca desaparece (Páez, 2020). Es un sobreponerse, un a pesar de las circunstancias, de estar en medio del campo, del conflicto, del olvido, casi de la nada y aún insistir.

\section{REFERENCIAS}

Arendt, H. (1996). La crisis de la educación. En Entre el pasado y el futuro. Ocho ejercicios sobre la reflexión política (pp. 185-208). Barcelona: Editorial Península.

CNMH (2017). Una guerra sin edad. Informe nacional de reclutamiento y utilización de niños, niñas y adolescentes en el conflicto armado colombiano. Colombia: Centro Nacional de Memoria Histórica.

Didi-Huberman, G. (2004). Imágenes pese a todo: Memoria visual del Holocausto. Barcelona Buenos Aires, México: Paidós.

Dussel, I. (2018). Sobre la precariedad de la escuela. En J. Larrosa (ed.), Elogio de la escuela. Buenos Aires: Miño y Davila.

Dussel, I. (2020). Visuality, Materiality, and History. En T. Fitzgerald (ed.). International Handbook of Historical Studies in Education. Sec- 
tion: Foundations and Directions (pp. 137-152). Estados Unidos: Springer Verlag. https://doi.org/https://doi.org/10.1007/978-98110-0942-6_8-1

Ezpeleta, J., y Rockwell, E. (1983). Escuela y clases subalternas. Cuadernos Políticos, (37), 70-80. http://www.cuadernospoliticos.unam.mx/cuadernos/contenido/CP.37/CP37.7JustaEzpeletaElsieRockwell.pdf

Fecode (2016). Escuela, territorio de paz. Centro de Estudios e Investigaciones Docentes -Fecode-, 1-10.

Felman, S. (2019). Testimonio. Crisis del testigo en literatura, Psicoanálisis e historia. España: Mármol-Izquierdo Editores.

González, M. (2016). El verdadero fin del conflicto armado: Jóvenes vulnerables, educación rural y construcción de la paz en Colombia. Norwegian Centre for Conflict Resolution [NOREF], 1-24.

Guevara, M. (2019, 31 de diciembre). 2019, el año más violento para los excombatientes de las FARC en Colombia. Noticias ONU. https:// news.un.org/es/story/2019/12/1467341

Herrera, M. C. (2016). Prólogo. Como el agua que fluye. Un prólogo para la paz. En P. Ortega (ed.). Bitácora para la Cátedra de la Paz. Formación de maestros y educadores para una Colombia en paz (pp. 19-24).

Herrera, M., y Pertuz, C. (2016). Educación y politicas de la memoria en América Latina. Por una pedagogía más allá del paradigma del sujeto víctima. Colombia: Universidad Pedagógica Nacional de Colombia.

Masschelein, J., y Simons, M. (2014). En defensa de la escuela. Barcelona: Miño y Davila. https://ifdmoreno-cba.infd.edu.ar/sitio/upload/ En_defensa_de_la_escuela.pdf

Masschelein, J., y Simons, M. (2018). La lengua de la escuela: ¿Alienante o emancipadora? En J. Larrosa (ed.). Elogio de la escuela (pp. 19-40). Barcelona: Miño y Davila.

Massey, D. (2009). Concepts of space and power in theory and in political practice. Documents d'Analisi Geografica, (55), 15-26.

Ospina, D., López, S., Burgos, S., y Madera, J. (2016). La paz entre lo urbano y lo rural: Imaginarios de paz de niños y niñas sobre el posconflicto en Colombia. Revista Latinoamericana de Ciencias Sociales, Niñez y Juventud, 16(2), 943-960.

Páez, Y. (2020). "Esto es tener ganas de estudiar". Una etnografía de dos escuelas rurales en tiempos del posacuerdo en Colombia. (Tesis de Maestría). Centro de Investigación y de Estudios Avanzados del Instituto Politécnico Nacional, México. 
Palomino, I. (2018). Los retos del posconflicto en San José del Guaviare. Colombia. Repositorio Universidad Del Rosario. https://repository.urosario.edu.co/sitios/retosPosconflicto/index.html

Pécaut, D. (2001). La tragedia colombiana: guerra, violencia, tráfico de droga. Revista Sociedad y Economia: Universidad Del Valle. Colombia, 1(sep.), 133-148.

Pertuz, C., Girón, C., Arévalo, G., Choachí, H., Torres, I., Merchán, J., Aponte, J., Garzón, L., Herrera, M., Ortega, P., Vega, R., Arias, R., Rodríguez, S., y De Currea-Lugo, V. (2019). Bitácora para la Cátedra de la Paz. Formación de maestros y educadores para una Colombia en Paz. En Bitácora para la Cátedra de la Paz. Colombia: Universidad Pedagógica Nacional de Colombia.

Restrepo, M. (2015). Con las escuelas rurales así, ¿¿cuál paz? Las 2 Orillas, Julio. http://www.las2orillas.co/con-las-escuelas-rurales-asi-cual-paz/

Riaño, P., Lacy, S., y Agudelo, O. (2003). Arte, memoria y violencia. Reflexiones sobre la ciudad. Colombia: Corporación Región.

Rockwell, E. (2009). La experiencia Etnográfica: Historia y cultura en los procesos educativos. Buenos Aires: Paidós.

Rockwell, E. (2018). Vivir entre escuelas. Relatos y Presencias. Antología esencial. Buenos Aires: CLACSO.

Romero, F. (2013). Conflicto armado, escuela, derechos humanos y DIH en Colombia. Análisis Politico. Universidad Nacional de Colombia, 26, 57-84.

Templeton, T. N. (2020). 'That street is taking us to home': young children's photographs of public spaces. Children's Geographies, 18(1), 1-15. https://doi.org/10.1080/14733285.2018.1550573 